\title{
O melhor amigo do homem: Afetos e cachorros NO BRASIL EM PERSPECTIVA SOCIOLÓGICA
}

\author{
Marcia da Silva MAZON*
}

\begin{abstract}
RESUMO: O artigo analisa a revista Seleções/Reader's Digest com o intuito de problematizar os efeitos do discurso a partir da idéia de comportamentos corretos ou heróicos tomando cachorros como mediadores. A revista destaca qualidades humanas em animais ao mesmo tempo em que separa quem enuncia (ou compila) daquele que é objeto do discurso. Com uma seção dedicada aos animais, observamos a comparação entre americanos e sul americanos expressa pelos comportamentos de animais, em particular o cachorro como parte da família. Os cachorros são mobilizados como mediadores entre o modelo ideal estadunidense urbanizado e a pacata e selvagem América do Sul a ser domesticada. A revista inaugura um ponto de vista dos animais explorando sua antropomorfização em contraponto a forma de agir dos sul-americanos. Este exercício se realiza no contexto das tensões da segunda guerra mundial e pósguerra.
\end{abstract}

PALAVRAS-CHAVE: Animais de estimação. Humanos e animais. Revista Seleções/Reader's Digest. Antropomorfização.

\section{Introdução}

Ganha fôlego no Brasil e no mundo a discussão sobre direito dos animais e ética animal. ${ }^{1}$ Isso contempla os animais que comemos (indústria de carne, laticínios, entre

\footnotetext{
* UFSC - Universidade Federal de Santa Catarina. Departamento de Sociologia e Ciência Política. Programa de Pós-Graduação em Sociologia Política (PPGSP) e Núcleo de Sociologia Econômica (NUSEC). Florianópolis - SC - Brasil. 88040-900 - marciadasilvamazon@yahoo.com.br. https://orcid.org/00000002-2953-1089.

${ }^{1}$ A publicação de Peter Singer de 1975 anuncia Libertação animal, livro cult do movimento antiespecista. A divulgação de vídeos sobre a violência banalizada em abatedouros e a publicação do ensaio de Aymeric Caron Antiespéciste reforçaram o antiespecismo que se declara igualitarista por oposição ao humanismo considerado como ideologia da dominação.
} 
outros) e os que amamos (animais de estimação). O direito dos animais ou bioética é considerado um avanço no campo da legislação comemorado como ampliação da esfera democrática no século XXI: ${ }^{2}$ animais, considerados como máquinas na visão cartesiana, são agora considerados seres sencientes: sentem dor. Essa expressão impulsionada pelo jargão jurídico no Brasil e em outros países altera códigos civis e inaugura o ambiente legal em que animais deixam de ser tratados como coisas e ganham o estatuto legal de seres dotados de sensibilidade.

No final do século XX e início do século XXI autores como Digard (2012) observam uma virada obscurantista: o excesso de zelo pelos animais de estimação (alimentado pela tese animalista ${ }^{3}$ ) implicando a denegação e diabolização do próprio ser humano e a relativização da ciência: o animalismo pressupõe a consideração dos animais pela ciência do ser humano e da sociedade ${ }^{4}$ (DIGARD, 2012). Há uma mudança igualmente no que toca aos mercados: intensificação da exploração dos animais que comemos (de granja) acompanhada da supervalorização e criação de um mercado de consumo tanto de objetos como dos próprios animais de companhia ${ }^{5}$ (DIGARD, 2012; MAZON; MOURA, 2017).

Seguindo a tese de Digard (2012) de que a relação entre humanos e animais de estimação (pet na expressão em língua inglesa) pode contribuir para entender a relação entre os próprios seres humanos, argumentamos como as formas discursivas sobre a relação entre humanos pode ser expressa através de animais como mediadores (BORGES, 2017). Elegemos para esta pesquisa os cachorros por serem os animais mais frequentes nos lares e a primeira espécie domesticada (MORELL, 2015).

Conforme dados do IBGE existem mais cachorros do que crianças nos lares brasileiros (RITTO; ALVARENGA, 2015). Os cuidados com animais e técnicas

\footnotetext{
2 As três posições filosóficas com relação ao direito dos animais: a cartesiana defende a natureza como privada de direitos. A republicana e humanista (Rousseau, Kant) entende que o ser humano é o único sujeito de direito, porém está ligado por deveres aos animais. O pensamento utilitarista de Peter Singer compreende que os animais compartilham com humanos a capacidade de sentir prazer e dor (FERRY, 1994).

${ }^{3}$ A palavra "animalismo" significa o deslocamento do centro de gravidade social e cultural dos seres humanos para os animais, que se fortalece com o ativismo animalitário (DIGARD, 2012). 0 ativismo animalitário alcança a tela do cinema em produções como Okja (2017) e Más notícias para o senhor Mars (2017).

${ }^{4}$ Novas especialidades científicas são criadas, como a arqueozoologia, etnociência na qual a etnozoologia e etnozootecnia ou ainda antropologia da domesticação animal se tornam especialidades (DIGARD, 2012).

${ }^{5}$ Há uma hierarquização entre animais de granja como a plebe e os animais de companhia como a elite: violência contra animais de granja, superproteção com os de companhia; ostracização com os primeiros e exposição ostentatória com os últimos (DIGARD, 2012).
} 
cirúrgicas específicas para eles igualmente avançam ${ }^{6}$ (SEGATA, 2012). Cinema e televisão aumentam os investimentos em produções dedicadas aos animais, alçando-os à condição de atores principais (aventuras de porcos, cachorros, etc.).

O cuidado e a proteção de animais mantiveram-se como assuntos pautados pela esfera religiosa. Desde a inspiração do Velho Testamento, a ordem divina surge como apelo ao respeito pelos animais. Note-se, não o respeito pelos animais em si, mas pelo efeito sobre a dignidade humana que o maltrato poderia provocar. Desde o final do século XIV, as leis de caça restringiram a propriedade de cães para essa finalidade apenas a pessoas acima de um determinado nível social ${ }^{7}$ (THOMAS, 2010). A imagem dos cães não permanece estável muito menos evolui numa mesma direção. Ainda conforme Thomas (2010), o cão podia ser encarado como vil e desprezível e ao mesmo tempo ser visto como o maior símbolo de virtude heroica, fidelidade. Entretanto o início da era moderna inaugura os pilares da obsessão pelos cães. No século XVIII o cão era conhecido como o mais inteligente entre os quadrúpedes e o servo mais fidedigno (THOMAS, 2010). Em 1700 todos os sinais de valorização dos cães estavam evidentes: traziam enfeites, plumas, anéis e fitas, sendo presença constante nos retratos das famílias. O surgimento das cidades e do sanitarismo inaugura uma tensão entre humanos e animais; animais domésticos úteis cedem espaço aos animais de estimação ${ }^{8}$ (OLIVEIRA, 2006) inúteis (MAZON; MOURA, 2017).

A partir do século XX, Thomas (2010) menciona a presença dos animais de estimação intensificada na Europa ocidental junto a uma população mais urbanizada, que mora em apartamentos. A ironia é que o animal vive num espaço apertado, em geral esterilizado e isolado da convivência com outros animais. Serpell (2003) observa uma antropomorfização dos animais pelos seus donos. ${ }^{9}$ Essa ironia é bastante sensível no momento presente: de um lado surge uma literatura médica que confirma forte relação positiva entre melhoria da saúde humana e a presença de pets nos lares (SERPELL, 1991; WELLS, 2009). De outro, essa presença é menos benigna; a adaptação ao nicho

\footnotetext{
${ }^{6}$ Um primeiro gato recebeu implante de patas na Inglaterra em 2009 e em 2017 outro recebeu implante de patas traseiras na Bulgária. Uma ONG de defesa dos animais financiou a operação com grande repercussão na mídia internacional (GATO..., 2017).

7 Uma lei do prefeito de Liverpool de 1567 determinava que mastins e cães de guarda fossem mantidos presos a fim de evitar prejuízos aos galgos, sabujos e spaniels; os três últimos, cães de fidalgos (THOMAS, 2010).

${ }^{8}$ Eram três os traços distintivos dos animais de estimação em relação aos demais: frequentavam o espaço interno da casa, recebiam um nome e jamais serviam de alimento (THOMAS, 2010).

${ }^{9}$ Antropomorfização é definida como atribuição de estados mentais humanos aos animais, fenômeno quase universal entre proprietários de pets: alimentar com comida humana, dar nome humano, fazer festa de aniversário, velório e enterro em cemitérios pet (SERPELL, 2003).
} 
dos humanos é responsável por severos problemas de bem-estar do próprio animal (SERPELL, 2003). O crescimento da presença de animais domésticos entre as classes médias urbanas é, para Thomas (2010), processo de envergadura social, psicológica e comercial. No entanto, conforme Digard (2012), longe de uma função catártica, remédio contra a solidão, esses animais fazem parte de um kit de felicidade da família perfeita da classe média francesa: o pet, a casa individual e o jardim. Mais da metade das mulheres entrevistadas num survey afirmam contar mais com o afeto de seus cães e gatos do que o de seus maridos e filhos (SERPELL, 2003), fenômeno igualmente mencionado por Segata (2016) no Brasil.

Então antes de refletir sobre o grau de afeto de humanos em relação aos seus cachorros de estimação no interessa iluminar como esta relação é preenchida segundo diferentes discursos. Outras pesquisas exploraram o discurso de ódio entre humanos que se agridem por meio de analogias envolvendo propriedades associadas aos cachorros (Borges, 2017). Este artigo tem como objetivo refletir sobre os discursos envolvendo as tensões internacionais que permeiam a segunda guerra mundial envolvendo propriedades associadas aos cachorros, mas não qualquer cachorro, aqueles nomeados como de estimação.

Interessa-nos entender o fenômeno pela chave dos efeitos dos discursos. Aqui analisamos uma revista, Seleções/Reader's Digest. Conforme Bourdieu (1976) os meios de comunicação como instrumentos de comunicação e de conhecimento são responsáveis pela transmissão de um consenso a respeito do mundo social e há uma constante luta pela imposição dos critérios de classificação da realidade. Este autor observa: "O poder das palavras não reside nas próprias palavras, mas, nas condições que dão poder às palavras criando a crença coletiva, ou seja, o desconhecimento coletivo do arbitrário da criação de valor que se consuma através de determinado uso das palavras" (Bourdieu, 2006, p.161).

Em outras pesquisas, Bourdieu $(2000,2005)$ mostra o momento de preenchimento do Estado francês com atores formados pelo pensamento liberal; a tomada de posição desses atores no sentido da defesa do mercado de casas próprias tem um efeito prescritor estimulando tanto oferta como demanda, e a aquisição de casas no mercado, como arbitrário cultural, se transforma em projeto e prioridade das famílias francesas.

Seguindo as pistas desses autores analisamos uma revista que participou da vida dos brasileiros no período da Segunda Guerra Mundial e pós-guerra, inaugurando um ponto de vista sobre animais de estimação: Seleções/Reader's Digest. Este artigo está apoiado em dados primários e secundários. Os dados primários são os conteúdos (matérias, carta ao editor, editorial) da revista Seleções no período de 1940 a 1960, os 
quais passaram por uma análise qualitativa de todas as matérias que se referiam aos cachorros (tanto como animal de companhia como objeto de pesquisa, animais de guerra e utilitários). Os dados secundários são estudos sobre a emergência da cultura de consumo no Brasil, literatura sobre história da família, história da criança no Brasil, história da vida privada no Brasil, assim como artigos científicos de diferentes áreas, que abordam os animais de estimação.

O foco é o período de emergência de uma sociedade urbana mais densa e a multiplicação dos veículos de comunicação e formação dos canais de ligação no país como estradas, correios, jornais. Interessa-nos explorar aspectos da sociogênese dessa intensidade de afeto em relação aos animais de estimação que se acomoda a uma esfera doméstica no Brasil mais adensado em sua trama urbana e industrial no período do pósguerra e sob particular influência dos EUA.

$\mathrm{O}$ artigo está dividido em duas seções. Na primeira analisamos a presença estadunidense no Brasil e a circulação de uma revista que, sendo estadunidense, foi umas das publicações mais difundidas em mais de cem países durante décadas, com milhares de exemplares vendidos e que fez igualmente sucesso a partir de sua primeira edição entre brasileiros: Seleções/Reader's Digest. Na segunda seção analisamos os conteúdos das matérias e compilações sobre cães para explorar os elementos mobilizados na construção da razoabilidade de cachorros nos lares como animais de estimação.

\section{O Brasil na primeira metade do século $X X$}

Por volta da década de 1930 o Brasil vive um momento civilizador (ELIAS, 1994): o aparelho de Estado se torna mais centralizado e o poder cada vez mais se desloca do âmbito regional para o nacional. O nacionalismo ganha ímpeto e o Estado afirma-se; essa tendência é acentuada com a criação do Estado Novo no período 19371945. Modificações profundas ocorrem a partir desse período. Com o fim da Segunda Guerra Mundial termina o Estado Novo e é eleita uma Assembleia Nacional Constituinte com a tarefa de pensar um novo modelo de organização administrativa e política. A partir de 1964 com a tomada de poder pelos militares há uma crescente centralização política, econômica e administrativa por meio da integração do mercado nacional, da implantação de redes de estradas, de telefonia, de comunicação de massa, da concentração de tributos no âmbito federal e do controle das forças militares estaduais pelo exército (OLIVEN, 2002). 
Se a implantação colonial, sob o jugo europeu, tinha como prática a exploração de matérias-primas e o cultivo de alimentos, a partir do século XX a expansão internacional do capitalismo industrial estadunidense transforma essa lógica. Calcada num padrão de industrialização intensivo em bens de consumo, investe na exportação de bens acabados: máquinas de costura, de escrever, automóveis, tratores, geladeiras. Com a Grande Depressão é urgente encontrar novos mercados para substituir as vendas internas nos EUA. Os países eleitos seriam aqueles que mais rápido se recuperassem dos impactos negativos da depressão mundial, como foi o caso do Brasil. Junto com as empresas que chegam ao país se somam as agências de publicidade. Elas se aproveitam dos avanços na qualidade da impressão com a prensa cilíndrica e do imenso parque de jornais e revistas (DURAND, 2013). As agências de publicidade assumem o comando da propaganda política quando os EUA declaram guerra à Alemanha e ao Japão: “[...] 'vender' a guerra aos estadunidenses era missão primordial, acenar com os confortos apresentados pelo regime da livre empresa era o foco principal"; o intuito era preparar o consumidor frustrado com a guerra para o momento em que as indústrias deixassem de produzir canhões e ofertassem geladeiras (DURAND, 2013, p.113).

Durante o regime autoritário da Revolução de 1930 e no Estado Novo o rádio é aberto à publicidade e promoção do governo. Cria-se um órgão central de controle da mídia: o Departamento de Imprensa e Propaganda (DIP). O governo estadunidense cria a seguir $A$ voz da América, noticiário com emissões em português para o Brasil. Umas das agências com filial no Brasil é a JWT. Seu diretor, Samuel Meek, que ocupou posições múltiplas entre governo e iniciativa privada, contribuiu para que a revista Seleções fosse implantada em diversos países (DURAND, 2013).

É nesse clima de mudanças que chega ao Brasil a revista Seleções. As revistas ilustradas serviam inicialmente como mídia de massa antes que esse papel fosse assumido pela televisão. A falta de imagens era substituída por peças gráficopublicitárias. Essa revista tem seu auge entre as décadas de 1940 e 1960. Ela começa a ser distribuída no Brasil no momento em que o consumo começa a ser estimulado. Esse é o momento de consolidação de atividades de mercado, fim da escassez de insumos e plena atividade dos parques industriais. A fonte de prazer era atribuída ao comércio de produtos industrializados; movimento estimulado pelo discurso otimista dos meios de comunicação. A revista contém várias peças publicitárias sobre os bens duráveis mencionados acima que os EUA desejam ofertar no mercado brasileiro. É interessante notar igualmente o privilégio metodológico de isolamento que Seleções proporciona: ela chega ao Brasil no momento em que ainda não havia uma distribuição nacional de mídias, ela vai ser a primeira (jornais e revistas eram distribuídos de maneira regional ou no máximo estadual), e igualmente quando a população atinge uma proporção de 
alfabetização significativa: se o censo de 1872 registra o mínimo de $11,5 \%$ de alfabetizados no Ceará e 27,4\% como máximo no Paraná (ALENCASTRO, 2008), em 1940 serão 49,74\% de homens alfabetizados e $41 \%$ de mulheres alfabetizadas no país (BELTRÃO; NOVELLINO, 2002).

\section{Seleções e seu contexto: difusão e compilação moralizante}

Ariès (2011) situa nos séculos XVII e XVIII o auge de um novo sentimento sobre a infância, uma preocupação em preservar a moralidade da criança. Educadores decidem impor seus escrúpulos e concepções proibindo a leitura de clássicos. Eles os reescrevem de maneira moralizante, preocupados com o pudor e o cuidado de evitar afrontas à castidade (ARIÈS, 2011). A revista Seleções trata-se igualmente de uma releitura, já que ela realiza a compilação de outras revistas e obras por editores de diferentes áreas, como veremos a seguir. Importante lembrar que o exercício de compilação já era conhecido no Brasil: entre os jornalistas existia o papel do "cozinheiro", aquele que editava notícias que haviam sido publicadas em outros jornais. No entanto, esse exercício era sempre regional, no máximo estadual, como mostra o biógrafo de Assis Chateaubriand, Fernando Morais (2011). Iniciando suas aquisições na década de 1930, entre elas a do Diário de Pernambuco (o primeiro jornal onde trabalhara), Chatô foi o proprietário de mais de cem jornais, uma agência de notícias inaugurada em 1931 - quando no mundo só existiam cinco agências de notícias (três europeias e duas estadunidenses) -, revistas e posteriormente emissoras de rádio e televisão (MORAIS, 2011). As mensagens da revista Seleções constituem uma nova moralização ou um manual de boas maneiras da sociedade que toma os cachorros como seres que participam dos lares e da vida doméstica.

Importante considerar a década de 1940 como o ano de intensificação das relações políticas, econômicas, militares e comerciais entre EUA e América do Sul sob a égide da política de "boa vizinhança" e sob os auspícios do pan-americanismo constituído por Washington (PRADO, 1995). A aliança construída pelos Estados Unidos com a América Latina durante o primeiro governo de Franklin Roosevelt tinha como objetivo afastar a influência dos países do Eixo. No Brasil essa política consistiu em negociações em vários setores, entre as quais um empréstimo para a construção da Companhia Siderúrgica Nacional em Volta Redonda, que se tornou carro-chefe da política nacionalista da era Vargas, além de um financiamento para as Forças Armadas, outra meta do Estado Novo (LIRA NETO, 2013; PRADO, 1995). Cabe aqui lembrar os procedimentos estadunidenses nos anos anteriores à Segunda Guerra Mundial. Com o 
temor do avanço da Alemanha na América do Sul o governo de Washington inicia uma mobilização diplomática em 1938; cria o órgão de divisão das Repúblicas Americanas com 14 escritórios, entre eles o de cooperação militar e comércio. Os Estados Unidos iniciam uma política de transmissão internacional de rádio no sentido de contrabalançar a propaganda alemã. No mesmo ano foi criada a Divisão de Relações Culturais do Departamento de Estado para incentivar a cooperação intelectual. Em 1940, incentivado por Rockfeller, o governo Roosevelt cria o Office of the Coordinator of Commercial and Cultural Relations, conhecido no Brasil como Birô Interamericano. Ele foi encerrado em 1946 e durante sua existência incentivou atividades no setor de comunicações, no setor cultural, entre outros. A área de comunicações compreendia rádio, cinema, imprensa, viagens e esportes ${ }^{10}$ (PRADO, 1995).

Foi momento marcante o ano de 1942, quando a revista Seleções ganhou sua versão em língua portuguesa no Brasil. Ela foi nomeada como a "revista da família americana". Conhecida pelas "piadas na caserna" e "meu tipo inesquecível", traz à memória a revista bem-humorada que alcança os lares brasileiros com sucesso entre as décadas de 1940 e 1960 (JUNQUEIRA, 1996). Ao mesmo tempo que transcende o espaço, divulga a experiência, concepção e crença dos estadunidenses. A revista começa a circular no Brasil dois meses após a entrada do país na Segunda Guerra Mundial. Sob o governo Vargas o país alinha-se ao bloco liderado pelos EUA (SCHERER Jr., 2014). No período da Segunda Guerra Mundial ela transpõe fronteiras e é lançada na Inglaterra em 1938 e no México em 1940, conforme seus editoriais. Na sequência, versões sueca, árabe, austríaca, alemã, japonesa e francesa. Todas as edições nos diferentes países foram sucesso imediato. Isso transformou Seleções no maior negócio de mídia impressa do século XX. A revista constitui-se durante a Guerra Fria como veículo a serviço dos aliados, iniciando sutil propaganda do American way of life, ideário da cultura americana.

Algumas das interpretações da Segunda Guerra Mundial se constituíram através dos textos e julgamentos binários emitidos por Seleções: o heroico soldado americano, o perigoso nazista, o dissimulado japonês (PRADO, 1995). A revista mostra os EUA como mundo harmonioso, visível e ordenado e contrapõe-se à América Latina fazendo referência às suas florestas: lugar do caótico, imaturo e desordenado. $\mathrm{O}$ homem americano ativo e empreendedor e o latino-americano passivo, atrasado, incapaz de

\footnotetext{
${ }^{10}$ No Brasil o programa de rádio Repórter Esso, patrocinado pela companhia de Rockfeller (Standard Oil), ficou famoso e ligado à imagem de uma fonte segura de informações. Foram estimuladas as agências de notícias estadunidenses como a United Press e a Associated Press, as quais desbancaram agências italianas e alemãs e garantiram sua presença quase exclusiva no mercado de notícias no pósguerra.
} 
dominar a natureza ao seu redor (JUNQUEIRA, 1996). Fazendo coro a essa interpretação igualmente os cachorros são alçados à condição de heróis, destemidos, como veremos na próxima seção. A revista opera na mesma chave das peças publicitárias, como mostra Bourdieu (2000, p.40) na análise do mercado de casas próprias: a publicidade só é tão eficaz porque "encoraja disposições preexistentes para melhor explorar submetendo o consumidor às suas expectativas e às suas exigências ao mesmo tempo em que aparenta servi-lo".

É possível observar os magazines de leitura rotineira como a revista Seleções como fonte de importação de ideias. O primeiro aspecto para o qual chamamos a atenção é o de que a revista teve por longas décadas grande distribuição, nos Estados Unidos inicialmente, e a partir da década de 1940 em diversos países. A tiragem de 1943 foi de 7 milhões de exemplares; em julho de 1944 foi de 11 milhões em cinco idiomas. Em junho de 1951 o editorial anuncia Seleções como a revista mais lida do mundo, com circulação mensal superior a 15 milhões e 500 mil exemplares. Em 1952 é editada em 11 idiomas e em dezembro de 1953 em 12 idiomas. O segundo aspecto se refere à atividade de compilação: a revista contrata editores de diferentes áreas e esses realizam uma seleção e condensação de artigos científicos, livros, outras revistas sobre assuntos corriqueiros do dia a dia, e organiza todas essas informações no mesmo patamar para o leitor comum com o mesmo grau de legitimidade, lembrando os compiladores dos clássicos da Grécia citados por Ariès (2011). Outrossim, quem confere essa legitimidade são os próprios editores ao eleger o assunto. Conforme Bourdieu (2001), a vida intelectual e artística, tutelada por instâncias externas até o final da Idade Média e Renascença, se liberta do comando da aristocracia e da Igreja com a constituição crescente de um público consumidor, um corpo de produtores e também pela multiplicação de instâncias de consagração e de difusão. O processo de autonomização da produção intelectual segue junto à constituição de uma categoria distinta de intelectuais (BOURDIEU, 2001). Quando mencionamos a constituição de um corpo de editores compiladores em Seleções, igualmente aqui se observa um movimento de diferenciação profissional.

Os leitores, por sua vez, poderiam ser desde chefes de Estado, cientistas e autoridades nacionais (que vez ou outra manifestavam seu apreço pela revista no espaço da contracapa, como espaço dos leitores) até donas de casa, presidiários e alunos de colégios que recebiam a revista gratuitamente (conforme notas dos editoriais).

No início (1922) a circulação máxima esperada era de 50 mil exemplares, mas no primeiro número serão 100 mil. No quinto número a revista chega ao Brasil e só aqui vendeu 150 mil exemplares. Em 1922 foram 5 mil exemplares enviados aos assinantes fundadores, e em 1942 "eram cinco milhões de exemplares saindo das rotativas do casal 
Wallace" (EDITORIAL, 1942, p.12). O ano de 1949 é de especial importância para os editores, já que se trata do momento da Convenção Pan-Americana e Convenção Internacional, que regulamenta os direitos autorais de reprodução de texto de outras fontes.

Seleções reunia à época 61 redatores, antigos diretores de revistas especializadas em publicações literárias, científicas, religiosas, comerciais e educativas. "Os editores lêem as melhores revistas e publicações especializadas, principais jornais e livros mais importantes com leitores em 105 países e de todas as idades e classes sociais. Lêem-se por igual, médicos e seus doentes, professores e seus alunos, patrões e seus empregados". (EDITORIAL, 1942, p.20, grifo nosso).

No Brasil, em 1942 a revista alcançou cidades do centro do país, além de outras localidades distantes, a exemplo do Acre, atendendo a 15 estados. O processo de distribuição de Seleções tinha um "representante geral" - Fernando Chinaglia, estabelecido na capital, Rio de Janeiro. O periódico só começa a ser editado e impresso no Brasil na década de 1950. O sucesso atingido pela revista Seleções estava relacionado tanto ao seu conteúdo quanto à sua forma de apresentação. ${ }^{11}$ A revista era mensal, continha, em média, 30 artigos e anúncios, um artigo para ser lido a cada dia do mês, além de resenha de uma obra considerada pelos editores de Seleções como significativa (SCHERER Jr., 2014). Os artigos eram escolhidos a partir de uma fórmula de julgamento elaborada pelo fundador do periódico, De Witt Wallace, e obedecia à seguinte máxima: 1) “é digno de ser lido?”; 2) “é aplicável aos interesses da maioria?"; e 3) "é de interesse permanente?". Vemos aqui o elemento dos manuais de boas maneiras conforme Elias (1994) discute em O processo civilizador, e ao mesmo tempo a formação de autoridade que legitima o que é digno de ser lido e o que pode ser considerado interessante. Igualmente como menciona Bourdieu (2001), o desenvolvimento de uma

[...] verdadeira indústria cultural e, em particular, a relação que se instaura entre a imprensa cotidiana e a literatura, favorecendo a produção em série [no caso da revista Seleções a compilação em série - de obras elaboradas segundo métodos semi-industriais] coincide com a extensão do público resultante da generalização do ensino elementar [como é o caso do Brasil à época] capaz de permitir às novas classes o acesso ao consumo cultural. (BOURDIEU, 2001, p.102).

\footnotetext{
${ }^{11}$ Entre magazines e outras publicações citadas como fonte para os artigos: Time, New York Times Magazine, Life, Scientific American, Nature, Chicago Daily News, Herald Tribune, Cosmopolitan, Saturday Evening Post, The Rotarian Variety, Christian Science Monitor, Catholic Word, Pan American, This Week, American Legion.
} 
Cabe ressaltar que a tônica geral das peças publicitárias sugeria para os leitores, de maneira simultânea, o contexto da Segunda Guerra Mundial e os "inimigos em comum" de "todos" os americanos, bem como os frutos colhidos pelos aliados no futuro do pós-guerra. A sociedade brasileira, através das mensagens e anúncios veiculados em Seleções, alcançava farto material para constituir os seus próprios significados do American way of life, embora os estereótipos estivessem bem definidos: demonizar alemães e países integrantes do chamado, na época, "Eixo do Mal" (SCHERER Jr, 2014).

\section{O cachorro como melhor amigo do homem: comparado com quem?}

A expressão "o melhor amigo do homem", conforme relato disponível na Wikipédia (GEORGE..., 2020) vem do estadunidense George Graham Vest, um senador que ficou conhecido pela defesa (na época em que era um advogado) de um fazendeiro que buscava justiça pela morte de seu cão provocada por um vizinho. Conforme os dados da Wikipédia o relato de Vest arrancou lágrimas, mas não só: tornou essa uma expressão automaticamente associada aos cães (quando usamos a expressão "o melhor amigo do homem", ninguém pensa em gatos, peixes ou papagaios). O discurso de Vest faz este exercício que é constante nos relatos de Seleções de comparação humanos/não humanos: compara cachorros com humanos, para identificar outros humanos como ameaça:

Senhores jurados, o melhor amigo que um homem tem neste mundo pode voltarse contra ele e tornar-se seu inimigo. Aqueles que estão mais próximos e são mais amados por nós - aqueles a quem nós confiamos nossa felicidade e nosso bom nome - podem tornar-se traidores desta confiança. O dinheiro que um homem tem, pode perder [...]. O único amigo desinteressado que um homem pode ter neste mundo egoísta - aquele que nunca é ingrato ou traiçoeiro - é seu cão. Senhores jurados, o cão permanece com seu dono na prosperidade e na pobreza, na saúde e na doença. [...] ele lamberá as feridas e as dores que aparecem nos encontros com a violência do mundo. [...] Quando todos os amigos o abandonarem, ele permanecerá. Se a fortuna arrasta o dono para o exílio, sem amigos e sem abrigo, o cão fiel não pede mais do que o privilégio de acompanhá-lo, a fim de protegê-lo contra o perigo, a fim de lutar contra seus inimigos. E quando a cena final se apresenta e a morte leva o dono em seus braços [...] não importa que todos os amigos sigam seu caminho; lá, ao lado de sua sepultura, se encontrará o nobre cão, [...] fiel e verdadeiro até à morte. (GEORGE..., 2020). 
Conforme o relato aquele que é capaz de uma vilania com um cachorro não merece ser qualificado como humano. Por meio dos cachorros as pessoas avaliam suas humanidades (Borges, 2017).

Importante considerar que a comparação entre humanos e outros animais não humanos que surge nos relatos de Seleções tem precedentes em outros registros no Brasil. O interessante é notar que até esse momento predominam os exercícios de zoofilização: humanos são comparados aos animais; o século $\mathrm{XX}$ traz a novidade inversa: a antropomorfização - animais passam a ser comparados com humanos. A zoofilização é um relato constante de Freire (2016) ao abordar o Brasil imperial e a situação dos escravos: eles são comparados e utilizados como cavalos e como mulas a tal ponto, segundo o autor, que esse processo adia a aquisição de cavalos pela corte no Rio de Janeiro e adia a instalação de um sistema de esgoto. ${ }^{12}$ Igualmente mobilizando a comparação de humanos com animais faz menção à "vadiagem" infantil no início da acomodação das classes trabalhadoras ao meio urbano no Brasil, nas palavras de Washington Luís no oficio ao comandante da Guarda Cívica:

Já temos a recomendarmos [...] aos que visitam estas numerosas matilhas de cães vagabundos e inúteis que uma mal entendida proteção enquadra de mais conveniente e imoralizado destino [...] e nosso desamor pela sorte de uma juventude que foge da escola e das fábricas para se viciar nas ruas [...]. (SANTOS, 2013, p. 220).

Falando do século XX, a revista Seleções foi inaugurada com o relato do heroísmo de um cachorro: um dos primeiros artigos da revista aborda a história de Rin Tin Tin, cão que se transformou em famoso personagem de TV estadunidense e, segundo a lenda contada pela revista, foi encontrado nos escombros da Primeira Guerra Mundial. Em episódios da série de televisão em que é o protagonista, ele salva humanos de outros humanos.

Seleções opera um trabalho cuidadoso de compilação e fornece valores, críticas, reflexões sobre diferentes temas incluindo uma coluna constante sobre animais de estimação, com particular atenção aos cachorros: de início cães úteis de guerra e ao longo dos anos os cães dentro das casas e no colo dos donos, desarrumando as camas ao

\footnotetext{
${ }^{12} \mathrm{~A}$ ausência de um sistema de esgotos e migração massiva de europeus (corte e burocratas) fez com que o Rio de Janeiro mobilizasse os tigres: nome com o qual eram chamados os escravos que despejavam dejetos domésticos nas praias. Alencastro (2008) sugere como motivo da expressão a cor tigrada dos escravos sujos.
} 
mesmo tempo que salvam vidas. No mesmo movimento em que a revista propõe formas de etiqueta, ela insere a razoabilidade dos cachorros nos lares.

Citamos na sequência exemplos de artigos que constituem a menção aos cachorros e o processo de antropomorfização conforme interpretado pelos editores da revista. Num artigo de junho de 1942 sobre um cão que impõe sua vontade e sua razão ao mesmo tempo que é desrespeitoso com humanos: "Eu queria comprar vários filhotes [...] decidi adquirir ao menos um bicho grande [...] Eu estava examinando alguns filhotes quando um deles aterrizou sentado nos meus pés [...] Eu acabara de ser escolhido [...]" (GOODMAN; GREEN, 1942, p.72). "O cachorro sabe que o dono é dele. Quando o dono começa a comer, o cachorro olha para ele e ganha a primeira garfada [...] Deixa seu terno desalinhado [...]" (GOODMAN; GREEN, 1942, p.73). Em outra publicação, de dezembro de 1942, o cão ataca humanos sob a cumplicidade da família: "[...] um cão com temperamento [...] mordeu mais de 40 convidados [...]" (THURBER, 1942, p.11). A mãe da família enviava bombons no Natal para compensar o constrangimento. Em março e maio de 1943, exemplos de antropomorfização: o dono viajava e o cão o aguardava e lhe trazia as pantufas. Morreu com as pantufas na boca. Um artigo de maio de 1943: o cão tinha ciúmes de outros cães: subia em todas as camas e as desarrumava quando sozinho. Em junho de 1943, em um artigo da American Kennel Gazette, dois exemplos de heró́smo: o cachorro que protege o gato e um cachorro que ajuda outro a tirar a mordaça (CACHORROS..., 1943). Em julho de 1943, o heroísmo e a comparação com humanos de um cão pastor-da-escócia: "Lembro dele melhor que de muitos homens e mulheres que já faleceram" (TERHUNE, 1943, p.16). Trazia o jornal para o dono. Ainda em julho de 1943 a imagem do cão herói e o anúncio de 40 mil cães selecionados para a guerra, cães que descobriam a posição do inimigo, mensageiros e padioleiros. Em janeiro de 1944, outro exemplo de antropomorfização: o cão mascote de um navio da guarda costeira norte-americana tinha suas tavernas preferidas e namoradas em cada uma.

Aqui é possível observar os mesmos efeitos da publicidade que Bourdieu (2000) encontra no mercado de casas próprias: a publicidade, segundo o autor, estaria relacionada ao encantamento; ela usa efeitos que podem ser considerados "poéticos", como os cães heróis salvadores. Com a poesia e "com efeitos perfeitamente semelhantes ela [publicidade] brinca com as conotações da mensagem, usando sistematicamente o poder que a linguagem poética detém de evocar as experiências vividas" (BOURDIEU, 2000, p.40). Bourdieu (2000) cita Marc Augé para falar da experiência do leitor de anúncios imobiliários explicitando as experiências subjetivas que os anúncios fazem surgir no seu espírito: o de homem citadino, cultivado; aqui, para os cachorros, homens e mulheres que inauguram a experiência urbana, industrial e em particular a experiência 
de estarem expostos a uma publicidade direta, aquela dos anúncios de eletrodomésticos, e indireta, que vai indicando lentamente a entrada mágica dos cães nas casas e nas experiências domésticas.

Um dos autores mais frequentes na menção aos cachorros em Seleções é Alan Devoe; sua participação tem um título particular: O melhor amigo do homem. Expressão que defende que o único amigo desinteressado de um ser humano é o seu cão, conforme já mencionado. As contribuições de Alan Devoe são em geral relatos de cães heróis e antropomorfizados e exercendo a razão. Em fevereiro de 1945 menciona um cão salvando outro de uma caverna; a revista de dezembro de 1945 apresenta um cão travesso até que a família é visitada por um cego e ele se torna educado, ou seja, ele pode repensar a sua maneira de agir.

Conforme o tempo passa os relatos ganham tons fantásticos e espetaculares: em dezembro de 1945 o cão advinha que seu dono (aviador da guerra) está em apuros no meio da mata e o salva, um cocker spaniel acompanha o dono no jogo de golfe e delata um caddie que havia roubado uma bola. Em abril de 1949, um cachorro que sobe as escadas com dificuldade para se despedir do dono antes de morrer, e em outro artigo do mesmo ano a cadela que esconde filhotes para que não sejam doados ao vizinho. $\mathrm{O}$ tom fantástico coincide com o final da Segunda Guerra Mundial, onde estadunidenses e aliados são anunciados em outros artigos da revista como os heróis da guerra.

A partir agosto de 1950 os artigos de Seleções ganham o tom de aconselhamento de como cuidar dos bichos, agora já parte dos lares: o cão deu tudo ao homem: amor, consolo, diversão, foi sentinela, cuidou de criança e do gado. No artigo de novembro de 1951 o animal como presença dos lares: ter cães é como ter mulher e filhos; "tira sua liberdade, mas você não vive sem eles" (ANGELL, 1951, p.74). Em maio de 1952 o artigo menciona o favorito da Scotland Yard - cão terra-nova que ganhou manchetes de rádio e televisão. Recebeu correspondência de fãs, foi afagado pela rainha Elizabeth. Apanhou mais de cem delinquentes em três anos. "Trabalhou melhor do que a maioria dos guardas" (MONAHAN, 1952, p.116). Em junho de 1952 se inverte a relação de autoridade entre o cão e seu dono e a presença dos cães nos lares se estabelece de forma completa: meu cão, meu dono. "Bem ensinado o homem pode ser o melhor amigo do cão. Eu pertenço a um setter inglês. Ele me adquiriu quando tinha 6 meses e vem me ensinando, hoje estou domesticado; nem todo cão consegue educar um homem, segredo de paciência" (FORD, 1952, p.76). O número de novembro de 1968 trata do último ritual da vida e de como adequá-lo ao novo membro da família: onde enterrar um cão. Em campos abertos; o melhor local no coração do dono.

Observa-se uma adaptação dos lares à sociedade de consumo que traz junto a aceitação dos cães e suas extravagâncias; no ponto de passagem os cães são os reis dos 
lares e seus donos apenas devem agir de forma a não ameaçar o bem-estar desses novos moradores; são os humanos que devem ser adestrados para lidar de forma civilizada com seus cães. O significado dos cães chega junto com geladeiras, máquinas de escrever e de costura; um kit de felicidade completo como mencionado por Digard (2012) e impulsionado pela especialização profissional da publicidade e dos compiladores no contexto da Segunda Guerra Mundial. Há uma relação de superposição que se alterna entre o animal útil e salvador e o animal folgado, essa relação reforça a presença dos cachorros nos lares como parte da nova sociedade de consumo no Brasil.

Seleções projeta uma imagem de cachorros como amigos leais dos humanos (contra outros inimigos humanos), heroicos (num período de guerras e da Guerra Fria) e mostrando relatos e histórias que chegam de diferentes fontes (de revistas náuticas cachorros heróis no mar; de revistas científicas - descobertas de como adestrar o cão; de revistas urbanas, religiosas ou não - da presença dos cachorros no cotidiano das pessoas e na hora sagrada da morte). Imagens que compõem um mosaico de um ser que, à medida que perde sua animalidade, ganha humanidade inclusive acima de outros humanos considerados fonte de frustração e decepção. Há uma tensão básica entre a utilidade do cão para os humanos e a possibilidade de os humanos serem úteis aos cães. Mais importante do que dizer se uma dessas leituras predomina é importante destacar como elas se reforçam na medida em que justificam a presença dos cães nos lares.

\section{Considerações Finais}

O início do século XXI Digard (2012) afirma uma mudança no estatuto cultural dos animais de companhia que secunda os humanos em relação aos primeiros. Os animais de estimação são parte da família, ali tratados como crianças ou são seus substitutos. Esperamos que este artigo possa contribuir para iluminar o fenômeno a partir das singularidades do Brasil.

Apontamos aspectos do arranjo institucional no Brasil no qual os cachorros de estimação fazem sentido, são investidos de significado e de como as pessoas avaliam suas humanidades através dos cachorros. Defendemos que pistas sobre esse processo podem ser encontradas nas publicações do período da Segunda Guerra Mundial e pósguerra, em particular em uma revista amplamente difundida no país: a revista estadunidense Seleções.

Ela começa a ser traduzida e publicada no Brasil no início da Segunda Guerra Mundial e ganha reconhecimento internacional nessa década de 1940. Ela serve como instrumento de propaganda dos ideais norte-americanos ao mesmo tempo que aborda 
alemães e japoneses como inimigos a serem temidos. Os cães aparecem como melhores amigos do homem, mas não só. Também como protetores dos homens contra outros homens, como era o espírito das duas guerras mundiais do século XX. Esse é o encaixe dos casos contados por diferentes publicações e posteriormente animados por cartas de leitores, os quais reproduzem casos épicos com seus animais de estimação. Esse periódico surge dentro do projeto de política de boa vizinhança dos EUA num movimento de aproximação da América do Sul a fim de evitar a influência da Alemanha. Seleções opera como um manual de boas maneiras no qual a melhor forma de viver é, entre outras sugestões, tratar os cachorros como o "melhor" amigo do homem, expressão que significa secundar humanos.

O artigo abordou a forma como a revista Seleções investiu cachorros de significados ao apresentá-los como animais domésticos, contribuindo por sua vez em uma transformação da relação entre humanos e não humanos. O artigo trouxe como reflexão o fato de que a revista operou na chave de peças publicitárias, uma vez que projetou uma imagem dos cachorros a partir de um papel moralizante, que educa a sociedade sobre como se relacionar com esses animais não só introduzindo-os nos lares, como também suprimindo o que eram consideradas como formas de tratamentos violentos e cruéis.

As pistas desta pesquisa indicam que a relação de humanos e cachorros é um entre outros caminhos para pensar a relação de humanos entre si, proposta já defendida por outros autores da sociologia e antropologia. Thomas (2010) alerta para o fato de as pessoas considerarem necessário para sua integridade pessoal criar um animal dependente, nos diz muito sobre a sociedade atomizada em que vivemos. Como na análise de Elias (1994), aqui igualmente brasileiros são convidados a uma contenção da libido: suportar as extravagâncias dos seus animais de estimação, que rasgam almofadas, mordem outros humanos, e recebê-los como heróis que são no espaço privado, ou que se tornarão, tudo a depender da atitude dos humanos. Aqui igualmente como em Thomas (2010) é possível observar aspectos de uma síntese da classe dominante: humanos que suportam extravagâncias de cães e, ainda, cães delatores de ladrões vigiando a propriedade privada.

\section{MAN'S BEST FRIEND: AFFECTIONS AND DOGS IN BRAZIL FROM A SOCIOLOGICAL PERSPECTIVE}

ABSTRACT: The article analyzes the Reader's Digest Magazine in order to problematize the effects of discourse from the idea of correct or heroic behaviors taking 
dogs as mediators. The magazine highlights human qualities in animals while separating those who enunciate (or compile) from those who are the object of discourse. With a section dedicated to animals, we observe the comparison between Americans and South Americans expressed by the behavior of animals, mainly the dog as part of the family. Dogs are mobilized as mediators between the idealized urbanized American model and the quiet and wild South America to be domesticated. The magazine introduced an animal point of view by exploring their anthropomorphization as a counterpoint to the South American way of acting. This exercise takes place in the context of the tensions of World War II and post-war.

KEYWORDS: Pets. Humans and animals. Reader's Digest magazine. Anthropomorphization.

\section{EL MEJOR AMIGO DEL HOMBRE: AFECCIONES Y LOS PERROS EN BRASIL EN UNA PERSPECTIVA SOCIOLÓGICA}

RESUMEN: El artículo analiza la revista Seleções / Reader's Digest para problematizar los efectos del discurso a partir de la idea de comportamientos correctos o heroicos tomando a los perros como mediadores. La revista destaca las cualidades humanas en los animales al tiempo que separa a los que enuncian (o compilan) de los que son objeto del discurso. Con una sección dedicada a los animales, observamos la comparación entre estadounidenses y sudamericanos expresada por el comportamiento de los animales, en particular el perro como parte de la familia. Los perros se movilizan como mediadores entre el modelo ideal urbanizado de los EE.UU. y la tranquila y salvaje América del Sur a ser domesticados. La revista inaugura un punto de vista animal al explorar su antropomorfización como contrapunto a la forma de actuar sudamericana. Este ejercicio tiene lugar en el contexto de las tensiones de la Segunda Guerra Mundial y la posguerra.

PALABRAS CLAVE: Animales de compañia. Humanos y animales. Revista Selecções / Reader's Digest. Antropomorfización.

\section{Agradecimentos}

Agradeço as críticas e sugestões da debatedora Maria Carman à primeira versão deste artigo no quadro do OP 153 - Science and technology of human and animal relationship 
no IUAES de 2018. Agradeço Antonio B. da Silva que me concedeu gentilmente acesso à sua biblioteca completa de Seleções tão bem como Mariza da Silva pelo apoio na conferência de referências.

\section{REFERÊNCIAS}

ALENCASTRO, L. F. Vida privada e ordem privada no Império. In: NOVAIS, F. (coord.). História da vida privada II: Império: a corte e a modernidade nacional. 9. reimp. São Paulo: Companhia das Letras, 2008. p.11-93.

ANGELL, R. Histórias de cães (condensado de Holiday). Seleções do Reader's Digest, Rio de Janeiro, p.72-75, nov. 1951.

ARIÈS, P. História social da criança e da família. Trad. Dora Flaksman. 2. imp. Rio de Janeiro: LTC, 2011.

BELTRÃO, K. I.; NOVELLINO, M. S. Alfabetização por raça e sexo no Brasil: evolução no período 1940-2000. Rio de Janeiro: Ministério do Planejamento, Orçamento e Gestão: Instituto Brasileiro de Geografia e Estatística: Escola Nacional de Ciências Estatísticas, 2002.

Disponível em: https://biblioteca.ibge.gov.br/visualizacao/livros/liv1425.pdf. Acesso em: 15 set. 2020.

BORGES, A. Cães e preconceitos na África do Sul: um diálogo entre literatura e etnografia. Horizontes Antropológicos, ano 23, n. 48, 2017, p. 225-252.

BOURDIEU, P. A produção da crença: contribuição para uma economia dos bens simbólicos. 3 ed., Rio Grande do Sul: Zuk, 2006.

BOURDIEU, P. O campo econômico. Política \& Sociedade, n. 6, p.15-58, 2005.

BOURDIEU, P. A economia das trocas simbólicas. 5. ed. São Paulo: Perspectiva, 2001.

BOURDIEU, P. As estruturas sociais da economia. Lisboa: Instituto Piaget, 2000.

BOURDIEU, P. Le couturier et sa grife: contribuition à une theorie de la magie. Actes de la Recherche em Sciences Sociales, n. 1, p.7-36, janv. 1976.

CACHORROS sabidos (condensado do American Kennel Gazette). Seleções do Reader's Digest, Rio de Janeiro, n. 17, p.48-49, jun. 1943.

CARON, Aymeric. Antispéciste. Réconcilier l'humain, l'animal, la nature. Dom Quichotte éditions, 2017. 
DIGARD, J.-P. Le tournant obscurantiste en Anthropologie: de la zoomanie à l'animalisme occidentaux. L'Homme, v. 203-204, n. 3, p.555-578, 2012.

DURAND, J. C. Agência de publicidade como escola: adesão ao sonho americano. In: CANEDO, L.; TOMIZAKI, K.; GARCIA, A. (org.). Estratégias educativas das elites brasileiras na era da globalização. São Paulo: Hucitec: Fapesp, 2013. p.108-129.

EDITORIAL. Seleções do Reader's Digest, Rio de Janeiro, tomo 1, n. 5, p.1-34. jun. 1942.

ELIAS, N. O processo civilizador: uma história dos costumes. Trad. Ruy Jungmann. Rio de Janeiro: Jorge Zahar Editor, 1994. 2 v.

FERRY, L. A nova ordem ecológica: a árvore, o animal, o homem. São Paulo: Ensaio, 1994.

FORD, C. Meu cão, meu dono (condensado do This Week). Seleções do Reader's Digest, Rio de Janeiro, p.75-77, jun. 1952.

FREIRE, G. Sobrados e mocambos. 15. ed. 3. reimp. São Paulo: Global, 2016.

GATO recebe implante de patas na Bulgária. Folha de S. Paulo, 28 jan. 2017. Disponível em: http:/www1.folha.uol.com.br/ciencia/2017/01/1853777-gato-recebe-implante-de-patas-nabulgaria.shtml. Acesso em: 15 set. 2020.

GEORGE Graham Vest. In: WIKIPÉDIA. San Francisco: Wikimedia Foundation, 2020.

Disponível em: https:/pt.wikipedia.org/wiki/George_Graham_Vest. Acesso em: 15 set. 2020.

GOODMAN, J.; GREEN. A. Preso por ter cão (condensado de How to Do Practically Anything). Seleções do Reader's Digest, Rio de Janeiro, n. 5, p.72-74, jun. 1942.

JUNQUEIRA, M. A. Seleções do Reader's Digest: o olhar norte-americano sobre a América Latina. História Revista, v. 1, n. 2, p.95-105, 1996.

LIRA NETO. Getúlio: do governo provisório à ditadura do Estado Novo (1930-45). São Paulo: Companhia das Letras, 2013.

MÁS NOTÍCIAS para o senhor Mars. Filme. Direção: Dominik Moll. Nacionalidades: França, Bélgica. Título original Des nouvelles de la planète Mars. Lançamento 18 de maio de 2017. Duração: 1 h $41 \mathrm{~min}$. Distribuição: IMOVISION.

MAZON, M. S; MOURA, W. G. Cachorros e humanos. Mercado de rações pet em perspectiva sociológica. Civitas: Revista de Ciências Sociais, v. 17, n. 1, p.138-158, 2017.

MONAHAN, J. O favorito da Scotland Yard (condensado do New Liberty). Seleções do Reader's Digest, Rio de Janeiro, p.109-116, maio 1952.

MORAIS, F. Chatô: o rei do Brasil. 4. ed. São Paulo: Companhia das Letras, 2011. 
MORELL, V. Evolução: do lobo ao cão. SCIAM, ano 13, n. 159, p.26-34, 2015.

OLIVEIRA, S. B. C. Sobre homens e cães: um estudo antropológico sobre afetividade, consumo e distinção. 2006. Dissertação (Mestrado em Sociologia e Antropologia) - Instituto de Filosofia e Ciências Sociais, Universidade Federal do Rio de Janeiro, Rio de Janeiro, 2006.

OLIVEN, R. Cultura brasileira e identidade nacional. In: MICELI, S. (org.). O que ler na ciência social brasileira: vol. IV. São Paulo: Anpocs: Sumaré; Brasília: Capes, 2002. p.15-44.

OKJA. Filme. Direção: Bong Joon Ho. Nacionalidades: Coréia do Sul, EUA, 2017. Duração: 120 min. Distribuição: Netflix.

PRADO, M. L. C. Ser ou não ser um bom vizinho: América Latina e Estados Unidos durante a guerra. Revista USP, São Paulo, v. 26, p. 52-61, jun./ago. 1995.

RITTO, C; ALVARENGA, B. A casa agora é dos cães - e não das crianças. Veja, 4 jun. 2015. Disponível em: http://veja.abril.com.br/noticia/entretenimento/a-casa-agora-e-dos-caes-e-naodas-criancas. Acesso em: 12 jan. 2016.

SANTOS, M. A. C. Criança e criminalidade no início do século XX. In: DEL PRIORE, M. História das crianças no Brasil. São Paulo: Contexto, 2013. p.210-230.

SCHERER Jr., C. A disseminação da cultura e da ideologia norte-americana no Brasil no contexto da II Guerra Mundial e o caso da revista Seleções Reader's Digest. Revista LatinoAmericana de História, v. 3, n. 10, p.7-22, 2014.

SEGATA, J. Quando o animal dura mais que a estimação. Mana, v. 22, n. 3, p.831-856, 2016.

SEGATA, J. Nós e os outros humanos, os animais de estimação. 2012. Tese (Doutorado em Antropologia Social) - Centro de Filosofia e Ciências Humanas, Universidade Federal de Santa Catarina, Florianópolis, 2012.

SERPELL, J. A. Anthropomorfism and anthropomorfic selection: beyond the 'cute response'. Society and Animals, v. 11, n. 1, p.83-100, 2003. DOI: 10.1163/15685300232093692.

Disponível em: www.researchgate.net/publication/233582872. Acesso em: 15 set. 2020.

SERPELL, J. A. Beneficial efects of de the ownership on some aspects of human health and behavior. Journal of the Royal Society of Medicine, v. 84, p. 717-720, 1991.

SINGER, Peter. Libertação Animal. 1975. Disponível em: https://olhequenao.files.wordpress.com/2011/12/peter-singer-libertac3a7c3a3o-animal.pdf. Acesso em 29 out. 2020.

TERHUNE, A. P. Meu cachorro inesquecível. Seleções do Reader's Digest, Rio de Janeiro, tomo IV, n. 18, p.14-16, jul. 1943. 
THOMAS, K. O homem e o mundo natural: mudanças de atitude em relação às plantas e aos animais (1500-1800). São Paulo: Companhia das Letras, 2010.

THURBER, J. O cachorro que mordia o dono (condensado de My Life and Hard Times).

Seleções do Reader's Digest, Rio de Janeiro, tomo II, no. 11, p.10-12, dez. 1942.

WELLS, D. L. The effects of animals on human health and well being. Journal of Social Issues, v. 65, n. 3, p.523-543, 2009.

Recebido em 20/08/2020.

Aprovado em 29/08/2020. 